\title{
Cultures in Aviation: Identification and Management of Cross-Cultural Factors in Multi-Cultural Aviation Maintenance Organizations
}

\author{
Sohail Akhtar Choudhry \\ Station Manager, KLM, \\ Dubai International Airport, Dubai, UAE
}

\begin{abstract}
This research uses the cross cultural approach to understand the human factors in aviation maintenance teams. The researcher examines the opinions of the Aircraft Maintenance Technicians (henceforth AMTs), Engineers and supervisors from two different organizations, regarding their attitudes about working in multicultural teams and how it impacts their performance. It also tries to understand the respondents' attitudes regarding stress, handling conflict, authority, fate etc. with reference to their national and cultural background. The study reveals that AMTs and their supervisors deviate from their expected national cultural traits; the ones from collectivistic cultures share the attitudes and beliefs of the ones from the individualist cultures and vice versa. The questionnaires and interviews with the Managers, supervisors and AMTs reveal their belief systems and stereotypes about their colleagues in the work place. It provides an insight in to the multi-cultural situation of these organizations and enables the researcher to make recommendations about improving the work-place environment.
\end{abstract}

Keywords: Aviation Maintenance, Multicultural teams, Cultures, Management

\section{Introduction}

There has not been much research done on the cross-cultural situation within multi-cultural AMT teams which could be because of several reasons. One reason could be the fact that most of the accidents in the field of aviation are believed to be caused due to the error of pilot and not that of engineer or mechanic. Whereas in reality, $12 \%$ of all major accidents in aviation are believed to be caused due to the error of maintenance personnel (Sears, 1986) Since the last few decades, the focus of research in the field of aviation shifted towards aviation maintenance teams and the situation of human factors in these teams. In today's global village, most of the AMT teams are multi-cultural, hence, the researchers tend to consider multi-cultural settings as a possible cause of the stressors which impact the job performance of AMTs. Considering the above mentioned scenario, the researchers in aviation tend to consider some of the basic issues like whether the human factors in aviation maintenance training are as valid in multi-cultural setting as they are in mono-cultural settings? or do we need to further sensitize aviation maintenance personnel to understand/adapt to the cultures of the people they are working with? To bridge up this gap, this research, like some other researches, uses the cross-cultural approach to study human factors in aviation maintenance. The research will try to understand how the various cultures interact within multicultural AMT teams and how do these interactions contribute to the efficiency of everyday operations or alternatively pose a threat to the safety of work place environment.

\section{Literature Review}

This section discusses the definitions of culture and multiculturalism, followed by some major research projects on cultures in aviation maintenance.

\subsection{Culture and Multiculturalism}

Culture is generally described as a set of norms, beliefs, values and social preferences which are shared by a group of people. Kawar (2012) observe that culture could be generic (shared by all the people on the planet) or local (specific to certain areas) Hofstede (1980) defines culture as "the collective programming of mind, distinguishing the members of one group or category of people from another."(Cited in Kawar, 2012, pp.105)Hence, culture makes one group of people different from the other. 
Hofstede $(1980,1991)$ conducted a research on the interactions of different cultures in the workplace. He defines culture as "the collective programming of mind distinguishing the members of one group or category of people from the other." He describes six dimensions of cultures which distinguish the members of one group of culture from another. Helmreich, Merritt and Wilhelm (1998) observe that out of the six, three of the dimensions were reproducible in the aviation. These are power Distance (PD), Individualism-Collectivism and Uncertainty Avoidance (UA).

Power Distance (PD) dimension refers to the degree to which the less powerful members of the society accept that the power distribution is unequal. The cultures exhibiting high degree of Power Distance have a hierarchical order in which everyone has a place and needs no further justification. The second dimension is IndividualismCollectivism (IC). The high side of it refers to the preference of loosely linked family structure in which individuals are motivated by their own preferences, needs and rights. In contrast, collectivism refers to a social pattern in which individuals are closely linked with each other. They prefer the benefit of the collective group over their individual rights. Al-Harabi (2002) observes that the individualist value heterogeneous groups whereas the collectivists value homogenous groups. They have different concepts on what causes someone to save face. Uncertainty Avoidance (UA) refers to the degree to which the individuals in a culture feel threatened by the uncertain situations. Hofstede maintains that the cultures exhibiting weak Uncertainty Avoidance, the rules are made and followed in cases of extreme necessity whereas the countries exhibiting high Uncertainty Avoidance are more prone to following rules and procedures. When replicated for research in Aviation, this dimension reflects the preference to follow the written procedures even when it is not in the best interest of the organization or doing otherwise. Hofstede's ideas were replicated in Aero-space Crew Research Project.

\subsection{SHEL Model}

SHEL model was initially given be Edwards in 1972 and later developed by Hawkins in 1984 (Hawkins and Orlady, 1993). The model proposes that various task -related situations interact with human beings to impact system's safety. The name SHEL takes after each of the components which interact with human beings in the work-place. They are as follows:

1.Software: In-tangible and non-physical aspect of aviation which governs how everyday operation has to be performed. It can be rules, standard operating procedures, policies, supervisor's commands etc. which are usually listed in manuals, charts, maps publications etc. (Wiener and Nagel, 1988)

2.Hardware: Physical aspects of aviation like aircraft, machines, tools, conveyer belt, vehicles etc.

3.Environment: It is the context in which aviation operates. It can include physical environment as well as social, cultural, economic and political factors.

4.Liveware :It refers to human beings in the work-place e.g. flight crew, maintenance personnel etc.

These factors do not work in isolation rather their interface with each other has to be studied to ensure safety in flight operations. These interfaces are:

\section{Liveware- Software:}

It refers to the interaction between human beings and procedural information. The safety in such interfaces can be compromised due to inappropriate procedures, ambiguous checklists or symbols, confusing or cluttered charts/graphs and inappropriate indexing of a manual. The software information is retained in human memory through training. Another possibility of compromise in safety is when aviation personnel are not sufficiently trained to understand or retain the information regarding software.

\section{Liveware-Hardware:}

It refers to the interaction between human beings and the machine. Liveware-Hardware match is successful if the aircraft is designed to meet the needs of human body such as comfortable seats, cockpit designs which match the sensory, information processing and movement characteristics of human body. The mismatch at livewarehardware can occur due to poorly designed equipment, poorly coded instruments or control devices etc.

\section{Liveware-Environment:}

Liveware-Environment refers to the interaction between human beings with their environment. LivewareEnvironment match is successful if the environment is according to the needs of human beings. 
The examples of it are Air-conditioning which controls the temperature, sound-proofing to reduce noise, pressurization systems to control cabin pressure etc. An example of mismatch at Liveware-Environment is reduced performance or errors resulting from disturbed biological rhythms (jet-lag) work-sleep patterns etc.

Liveware-Liveware

It refers to the interaction between human beings performing various tasks. Its examples are communication between pilots and ATC, pilots and maintenance personnel, investigator with the flight crew etc.

Wiener and Nagel (1988) observe that any change in SHEL system requires consideration of its impact on the system's safety. For example, any equipment change (hardware) would require training of the personnel using it to ensure safety at Liveware-Hardware level.

SHEL model places human beings at the center of the whole system; hence human factors are of key importance while ensuring safety. Aerospace crew research project was another milestone as it has shifted focus from the individual human beings to the teams in aviation. While researching the work-place dynamics in aviation, the project focused on how various cultures interact and could contribute or demise system's safety.

\subsection{Aerospace Crew Research Project}

One of the notable researches in exploring the work place dynamics in aviation is Aerospace Crew Research Project. The research project generated data about the interaction of cultures through questionnaires and direct observation of multicultural AMT teams. The project aimed at answering the following research question "To what extent, and in what areas are pilots' work-related attitudes universal, i.e. part of a professional pilot standard and to what extent are they influenced by national culture?" (Merritt, 1996) The study revealed that the pilots from all nationalities researched have almost similar responses towards issues like "Communication and Team work", "Attitudes towards Stress", and "Organizational Climate." The responses vary significantly over issues like "Command Interactions/Structure" and "Tolerance for Rules, Routines and Set Procedures"

Merritt (1996) observed that while answering the questions on the issues relating "Communication and Team Work" the respondents from Asian countries believed that a post flight debriefing and critique by the Captain is important whereas the respondents from Anglo countries didn't favor the post-flight, captain-led, open performance appraisal.

Another significant finding of this project was that the majority of the pilots surveyed showed an unrealistic attitude towards "Stress". Merritt et al. (1996) conclude that the pilots across various nationalities believe that stress is a sign of weakness in a truly professional aviator. Hence, this invulnerable image of an aviator results in more likelihood of human error and effective human error management will be even more difficult to achieve.

The responses on the third issue, Organizational Climate generated different responses from the pilots from different airlines. Westrum (1996) describes organizational climate as the pilots' appraisal of the culture in an organization. It refers to the degree of harmony between an individual pilot's values and the company's environment. The results highlighted that if the organizational culture is similar to the individual pilot's values, he would enjoy his job and consider the airline as a large family.

The scale of "Command Interactions/Structure" revealed variable responses from the respondents belonging to different countries. Merritt (1996) notes that the pilots from Taiwan gave relative priority to the rules and precision, Brazilian pilots favored rank and predictable routine whereas the pilots from Philippines favored relational hierarchies. In general, the preferences of respondents were broadly categorized between Egalitarian Command Style Vs. Hierarchical Command Style. Egalitarianism refers to the belief that all human beings are equal and seniority of a captain in relation to the crew is a temporary reality. Such a command style is followed by the respondents from Anglo countries. In contrast, the Hierarchical Command Style refers to the belief that all human beings are not created equal. The relational hierarchies dictate one's place in a family/society and it is the duty of an individual to accept his place.

The Attitudes towards Automation refers to the pilots' preference/non-preference for automated flying. Sherman, Helmreich and Merritt (1997) observe that the respondents from individualistic cultures such as US, Ireland, the UK and the Australia prefer to assert themselves in their interaction with FMC whereas the respondents from hierarchical national cultures see FMC as a high status crew member which must not be questioned at any cost. Concluding, the Aerospace Crew Research Project revealed that none of the national cultures could be considered conducive or non-conducive to the aviation safety as a whole. Every culture has some aspects which may contribute or detract from the safety. 
Furthermore, Hofstede's Dimensions of Culture is seen as a major influence behind Aerospace Crew Research Project (Already discussed in the beginning of this section). Following the similar research methodology, the present research uses Hofstede's dimensions of culture as used in Aerospace Crew Research Project, to identify the expected work-related attitudes of the aviation maintenance personnel. The data will be collected through questionnaires and the analysis will provide an insight into the work-related behaviors of the participants.

\section{Research Questions}

The research aims at answering the following research question:

How do the national cultures of aircraft maintenance personnel impact their workplace attitudes and their response towards the cultures of their colleagues?

While doing so, the research will also address the following questions:

1. Do the multicultural settings create stressors which affect job performance? Do the differences of language, culture, religion etc. would negatively impact the job performance?

2. Do the aviation maintenance organizations chosen for the research effectively manage the cultural diversity in their teams?

\section{Research Methodology and Sample Selection}

The data for this research is generated through questionnaires and interviews. The items of the questionnaire have been framed from Flight Management Attitude Questionnaire (FMAQ) to determine the attitudes of the maintenance personnel to know how similar or different they are from their expected national cultures (Hofstede: 1980,1981) The data generated is expected to reveal the attitudes of the respondents regarding the issues like stress, authority, responsibility and the style of communication they prefer.

The two airlines chosen for the research are a ${ }^{1}$ European Airline and a Middle Eastern Airline. The participants of the research were based in the Middle Eastern stations of these airlines and belonged to different cultures. The number of questionnaires received is uneven with respect to the ethnicity and nationality. Hence, the researcher has grouped the respondents in to cultural groups, to have a uniform set of data. The culture group variable has been used by Hofstede (1980,1981) Lewis (1997) and Rolls Royce (2001) in their influential studies. For this research, the participants are grouped into 6 culture groups. For each culture group, equal number of participants has been randomly selected to participate in the study. In total, sixty respondents filled up the questionnaires. The break-down of the nationalities of the respondents is as follows:

Table 1. Breakdown of respondents with respect to cultural groups

\begin{tabular}{|l|l|}
\hline Hindu culture group & 10 \\
\hline Muslim culture group & 10 \\
\hline Buddhist culture group & 10 \\
\hline Christian Filipino culture group & 10 \\
\hline Anglo culture group & 10 \\
\hline Latin culture group & 10 \\
\hline
\end{tabular}

The respondents' attitudes regarding the four scales are analyzed to understand how the attitudes of Aircraft maintenance personnel are similar or different from their expected national cultural attitudes (as outlined by Hofstede, 1980). Furthermore, the researcher will try to see how these attitudes contribute to or cause a threat to the safety of the flight operations. For the analysis of national cultures, all sixty respondents' attitudes are analyzed collectively.

\footnotetext{
${ }^{1}$ To maintain privacy and confidentiality, the researcher will not disclose the names of the organizations chosen for the research. To provide background information, a brief overview of both the organizations is provided. The European Organization is one of the world's oldest airlines. It has a fleet of 119 Aircraft and operates to 145 destinations in the world. In 2004, it merged with another European Airline. Currently around 84,602 employees work in this airline which is now a merger of two airlines..

The Middle Eastern Organization was founded in 1985. It has a fleet of 265 Aircraft which fly to 155 destinations around the globe. Around 64, 768 employees currently work in this airline. 


\section{Analysis and Results}

This section analyses twenty six attitudinal items of the questionnaire. The items analyzed in this chapter fall into the four categories: Command Responsibility, Communication and Coordination, Recognition of stressor effects, Avoiding Conflict, Goal Attainment with Others

\subsection{Five Scales of Analysis}

Respondents' attitudes with respect to the four scales of analysis are as follows:

\section{a. Communication and Coordination}

Hofstede (1980, 1981) believed that Communication and Coordination scale reflects Power Distance. Good communication and coordination reflects low Power Distance and egalitarian command style while less communication and co-ordination reflects high Power Distance. 6 items in the questionnaire are analyzed to identify the attitudes regarding communication and coordination. The findings are as follows:

$80 \%$ of the Hindu group, $70 \%$ of Muslim group, $70 \%$ of Buddhist group agree that good communication or coordination is important for safety. The results from Christian Filipino (70\%), Anglo (100\%) and Latin (100\%) groups are also similar.

The second item in the category "Debriefing/critique is important for safety," reveals slightly different results: Anglo and Latin culture groups (100\% each) agree that debriefing/critique is important for safety whereas fewer members of Hindu, (70\%) Muslim, (60\%) Buddhist (50\%) and Christian Filipino (50\%) agree with the statement. It indicates that the members from the collectivist cultural groups are more prone to saving face and respecting the authority of their superiors.

Almost all the cultural groups strongly agreed with the statement 3 "Training is an important management responsibility" and 5. "Pre-assignment briefing is important" but statement 4 and 6 "Coordination is more important in emergencies" and "Coordination requires taking other personalities into account" respectively again drew different responses from the cultural groups.

Statement 7 again reflects the different cultural tendencies. The collectivistic cultural groups see coordination as a managerial responsibility whereas Anglo and Latin cultures group members disagree and believe that coordination with others is the responsibility of team members themselves. All these results reveal that despite the respondents belonging to individualist or collectivist cultures, they experience good communication and coordination and less Power Distance in their organization. Hence, they won't agree blindly to their superiors rather voice their concern.

\begin{tabular}{|l|l|l|l|l|l|l|}
\hline & Hindu & Muslim & Buddhist & $\begin{array}{l}\text { Christian } \\
\text { Filipino }\end{array}$ & Anglo & Latin \\
\hline St. 1 & $80 \%$ & $70 \%$ & $70 \%$ & $70 \%$ & $100 \%$ & $100 \%$ \\
\hline St. 2 & $70 \%$ & $60 \%$ & $50 \%$ & $50 \%$ & $100 \%$ & $100 \%$ \\
\hline St. 3 & $100 \%$ & $100 \%$ & $100 \%$ & $100 \%$ & $100 \%$ & $83 \%$ \\
\hline St. 4 & $60 \%$ & $60 \%$ & $70 \%$ & $70 \%$ & $100 \%$ & $100 \%$ \\
\hline St. 5 & $100 \%$ & $100 \%$ & $100 \%$ & $100 \%$ & $100 \%$ & $100 \%$ \\
\hline St. 6 & $60 \%$ & $50 \%$ & $60 \%$ & $70 \%$ & $100 \%$ & $100 \%$ \\
\hline St. 7 & $100 \%$ & $100 \%$ & $80 \%$ & $80 \%$ & $60 \%$ & $60 \%$ \\
\hline
\end{tabular}

Table 2. Comparison of number of participants from each cultural group who agree with the statements in Communication and Coordination Scale 


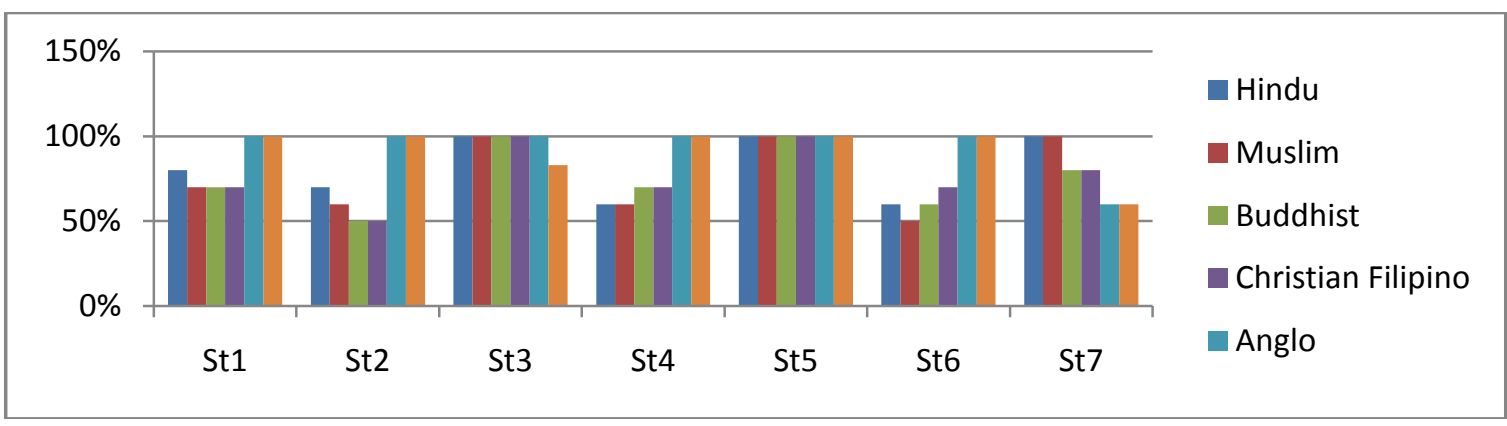

Figure 1. Comparison of number of participants from each cultural group who agree with the statements in Communication and Coordination Scale

\section{b. Command Responsibility}

The attitudes regarding Command Responsibility are tested through four items in the questionnaire (St.8-11) When more participants agree with the statements 8,9 and 11, it reflects a hierarchical style of command and high Power Distance. When the participants do not agree with the statements mentioned in the category, it reflects an egalitarian command style and less Power Distance which is a characteristic of collectivistic culture. Referring to St.8 (Managers should take charge in emergencies) $80 \%$ of Hindu group, $100 \%$ of Muslim group, $70 \%$ of Buddhist group agree with the statement. The participants from Anglo, Christian Filipino and Latin groups disagree with the statement. The participants from the collectivist cultures believe that the leader or the manager should take decisions in emergency situations, which is not true for the people from individualistic cultures. For them, a crisis has to be dealt as a combined effort and everyone's opinion matters. Hence the results here are in line with Hofstede's views about cultures. St. 9 (We should not question superiors' actions) reveals the surprising results as the groups from collectivistic cultures like Muslim, Hindu and Buddhist disagree with the statement. In collectivistic cultures, the actions of superiors should not be questioned as it causes them to lose face (or wajha, in Arab) however, the results here reflect a different tendency. It is favorable to the maintenance departments, as the AMTs and Engineers would not blindly agree with their superiors' actions rather they would voice their concern. St. 10 (Subordinates should not take control) reveals similar results; $70 \%$ of Hindu group, $60 \%$ of Muslim group, $70 \%$ of Buddhist group agree with the statement. None of the European, American or Filipino group member agreed with the statement. The results again reflect the similar tendency from the participants of the collectivistic cultures; they believe that subordinates should be made a part of command and control.

St. 11 Technical proficiency causes successful management reveals attitudes regarding what makes a successful manager. Theoretically, the people from collectivist cultures believe that social status and familial ties decide who should be the leader of the clan whereas the people from the individualist group think otherwise. For them, the skill and proficiency of an individual should be deciding factor in the ascent to a higher position. The results reveal that $80 \%$ of the Hindu group, $80 \%$ of the Muslim group, $70 \%$ of the Buddhist group agrees with the statement. American, Filipino and European groups also agree in large numbers with the statement. The results reveal that the airlines chosen for the analysis have employees who believe that skill and hard work leads to the promotion, not the family ties or race. Hence, everyone would like to develop their skill to be promoted.

\begin{tabular}{|l|l|l|l|l|l|l|}
\hline & Hindu & Muslim & Buddhist & $\begin{array}{l}\text { Christian } \\
\text { Filipino }\end{array}$ & Anglo & Latin \\
\hline St.8 & $80 \%$ & $100 \%$ & $70 \%$ & $60 \%$ & $60 \%$ & $60 \%$ \\
\hline St.9 & $30 \%$ & $30 \%$ & $40 \%$ & $20 \%$ & $0 \%$ & $0 \%$ \\
\hline St. 10 & $50 \%$ & $50 \%$ & $30 \%$ & $0 \%$ & $0 \%$ & $0 \%$ \\
\hline St. 11 & $80 \%$ & $80 \%$ & $70 \%$ & $80 \%$ & $100 \%$ & $100 \%$ \\
\hline
\end{tabular}

Table 3. Comparison of number of participants from each cultural group who agree with the statements in Command Responsibility Scale 


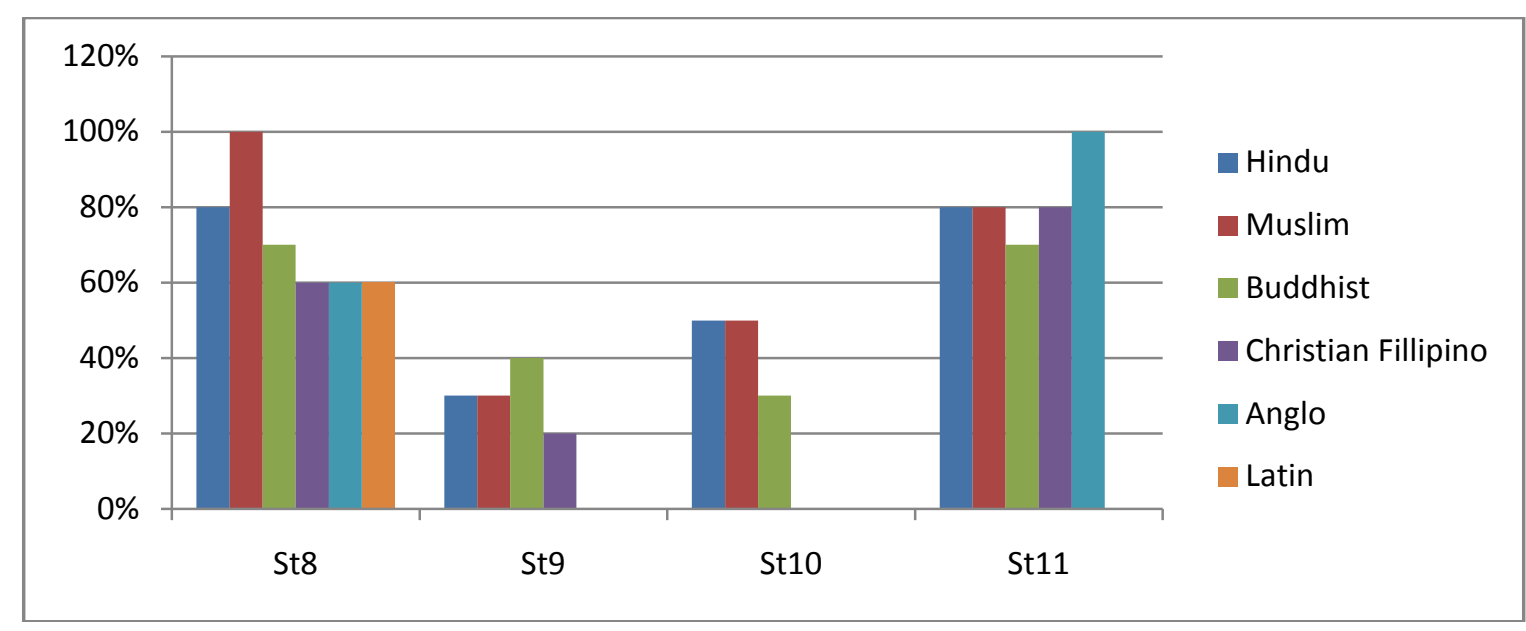

Figure 2. Comparison of number of participants from each cultural group who agree with the statements in

\section{c. Avoiding Conflict}

Command Responsibility Scale

St. 12 to14 reveal the attitudes of the participants regarding Avoiding Conflict. None of the members of the European and Dutch groups agree with the statement 12 because in Individualist cultures, disagreement is considered healthy and normal for the growth of an organization and an individual. However, some members from Hindu, Arab, Buddhist and Christian Filipino cultural groups agree with the statement. The results here are not exactly similar to that of Hofstede's findings that the members from the individualist cultures see disagreement as a mandatory aspect of a successful organization whereas the members of the collectivist cultures believe that disagreement begets discord and in the long run, destroys the harmony of a group.

Hence, the results here have a positive ramification for the organizations chosen for the study. It shows that the participants will speak up against each other and their supervisors if they notice that operations' safety has been compromised. Statement 13 reveals attitudes regarding personal opinion of group members about each other.

Almost all the group members, from both collectivist and individualist cultures agree with the statement that they must avoid passing negative comments about each other. The statement is not clearly worded and it does not clarify whether it refers to passing negative comments on others as a person or passing negative comments as a result of technical errors of others. The results reveal healthy ramifications for the airlines if the respondents are referring to negative personal comments about their colleagues.

Statement 14 Casual conversation improves coordination again is agreed upon by most of the groups. Both collectivist and individualist cultural members agree with the statement. The statement has a positive ramification for the organization because casual conversation is the first step towards improving coordination.

\begin{tabular}{|l|l|l|l|l|l|l|}
\hline statements & Hindu & Muslim & Buddhist & $\begin{array}{l}\text { Christian } \\
\text { Filipino }\end{array}$ & Anglo & Latin \\
\hline $\begin{array}{l}\text { Statement } \\
12\end{array}$ & $40 \%$ & $50 \%$ & $50 \%$ & $40 \%$ & $0 \%$ & $0 \%$ \\
\hline $\begin{array}{l}\text { Statement } \\
13\end{array}$ & $80 \%$ & $80 \%$ & $80 \%$ & $70 \%$ & $70 \%$ & $70 \%$ \\
\hline $\begin{array}{l}\text { Statement } \\
14\end{array}$ & $80 \%$ & $90 \%$ & $90 \%$ & $70 \%$ & $80 \%$ & $80 \%$ \\
\hline
\end{tabular}

Table 4. Comparison of number of participants from each cultural group who agree with the statements in Avoiding Conflict Scale 


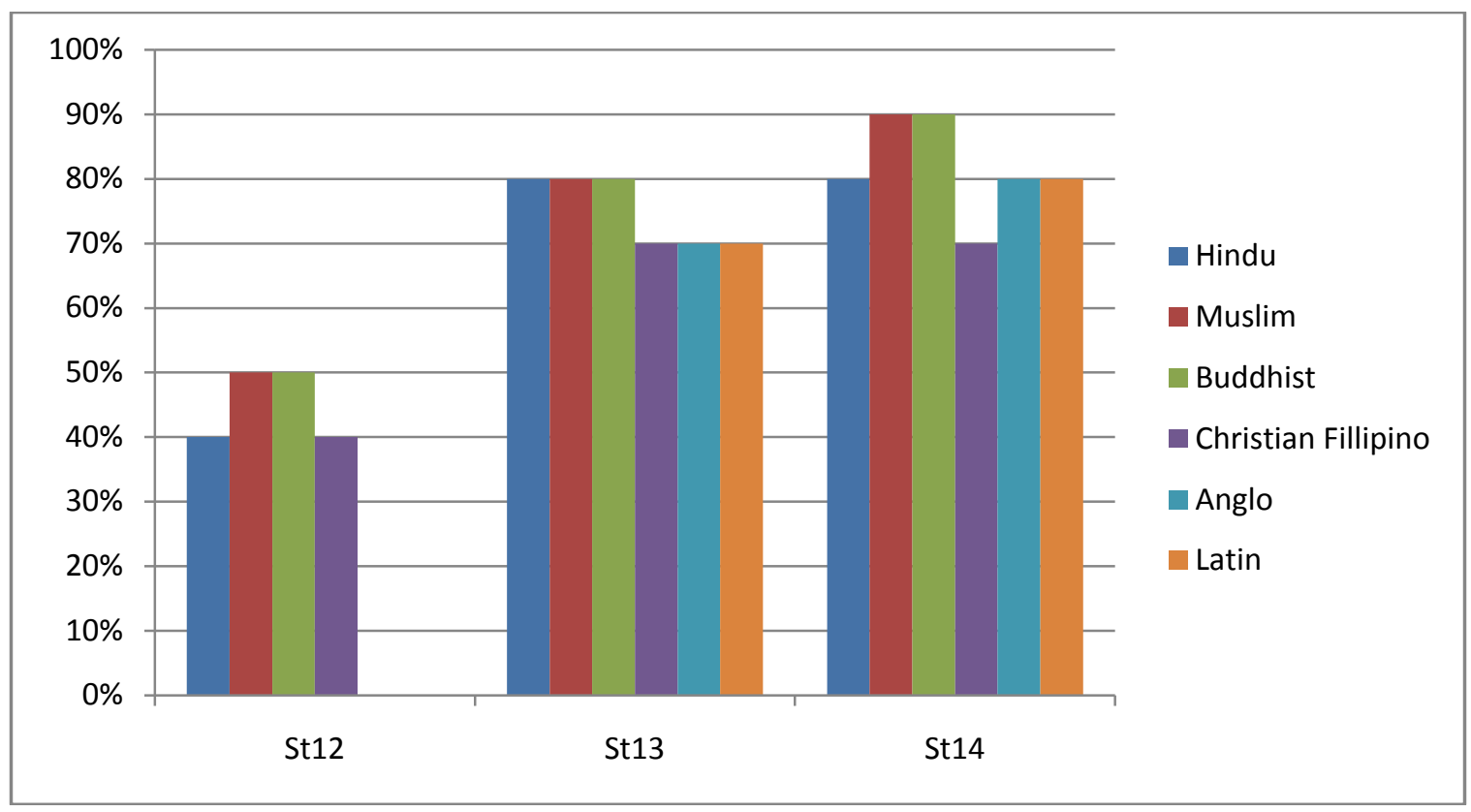

Figure 3. Comparison of number of participants from each cultural group who agree with the statements in

\section{d. Recognition of Stressor Effects}

Avoiding Conflict Scale

Statements 15 to 20 reveal attitudes about whether the participant recognize and acknowledge the stress effects in themselves and others or not. The results here are not alarming because none of the participants showed in large numbers the presence of fatalistic outlook. Fatalism is associated with collectivistic cultures and is considered antithetical to the safety issues. Almost all the cultural groups agree with the statement 15 We should be sensitive to other people's problems. Statement 16 again is agreed upon in large numbers however, statement 17 I perform effectively when fatigued reveals alarming results from some cultural groups. Some of the collectivist cultural groups agree with the statement in large numbers which shows their tendency to ignore the effects of stress on their performance. Statement 19 Managers can leave their personal problems aside reveals similar results from the collectivist culture groups. These cultures have the tendency to see managers as omnipotent father-like figures, devoid of weaknesses. Such an attitude can be detrimental to the safety of the organization.

The last statement in the category My decision making is good in abnormal situations reveals slightly different results. Almost all the cultural groups disagree with the statement which has a positive ramification for the organization.

\begin{tabular}{|l|l|l|l|l|l|l|}
\hline & Hindu & Muslim & Buddhist & $\begin{array}{l}\text { Christian } \\
\text { Filipino }\end{array}$ & Anglo & Latin \\
\hline St.15 & $80 \%$ & $80 \%$ & $70 \%$ & $70 \%$ & $50 \%$ & $60 \%$ \\
\hline St.16 & $70 \%$ & $70 \%$ & $60 \%$ & $100 \%$ & $100 \%$ & $100 \%$ \\
\hline St. 17 & $80 \%$ & $90 \%$ & $80 \%$ & $20 \%$ & $0 \%$ & $20 \%$ \\
\hline St. 18 & $50 \%$ & $70 \%$ & $70 \%$ & $90 \%$ & $90 \%$ & $100 \%$ \\
\hline St 19 & $90 \%$ & $80 \%$ & $90 \%$ & $60 \%$ & $20 \%$ & $20 \%$ \\
\hline St.20 & $40 \%$ & $30 \%$ & $40 \%$ & $30 \%$ & $30 \%$ & $20 \%$ \\
\hline
\end{tabular}

Table 5. Comparison of number of participants from each cultural group who agree with the statements in Recognition of stressor effects scale 


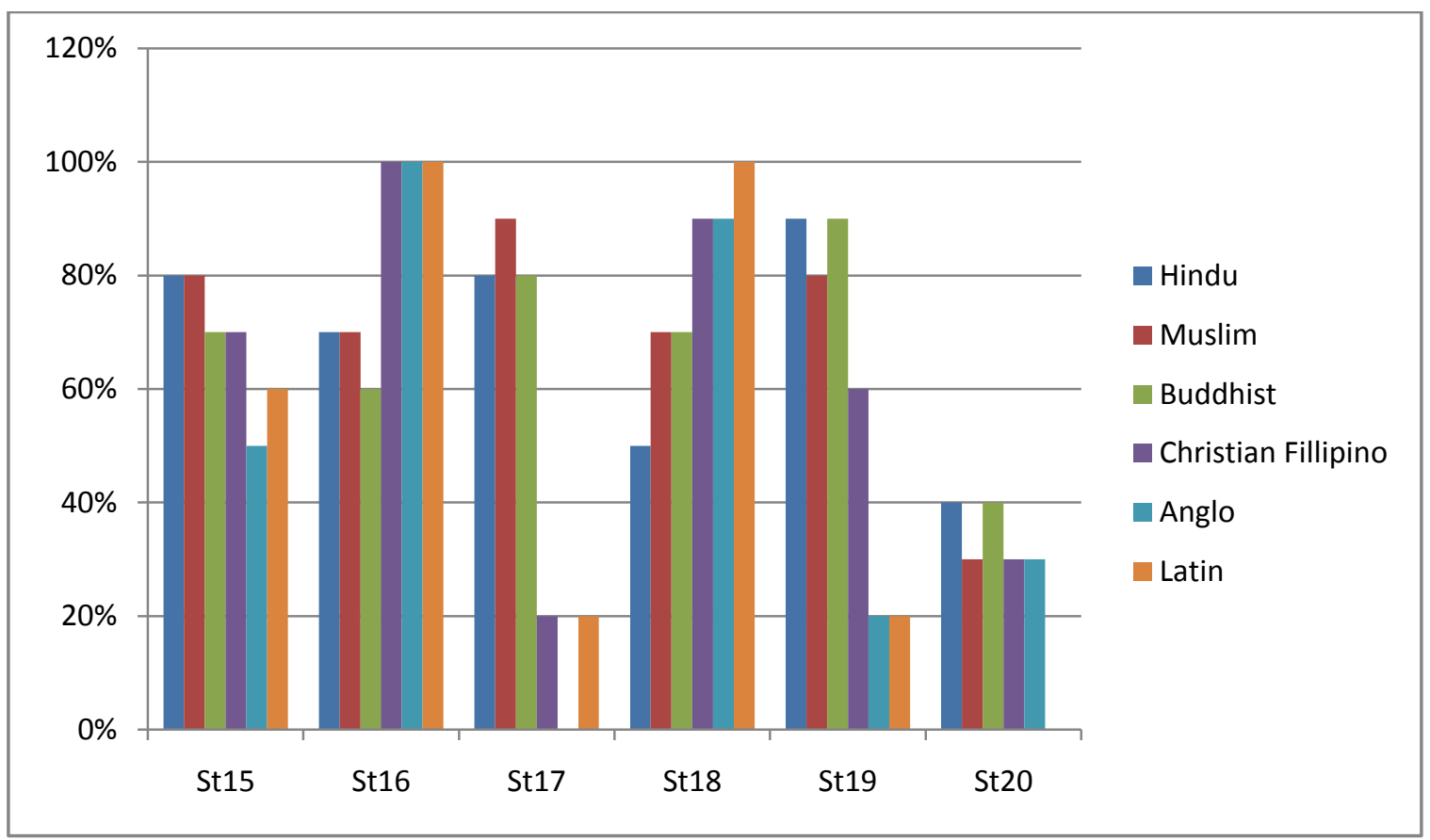

Figure 4. Comparison of number of participants from each cultural group who agree with the statements in Recognition of stressor effect scale

\section{e. Goal Attainment with Others}

Statements 21 to 26 reveal attitudes regarding "goal attainment with others." The items in this category have been framed to tap into the issues of Individualism-Collectivism. When the participants agree on work goals or collectively set their work place goals, it reveals a tendency of collectivist cultures.

Most of the participants agree with the statement 21, 22 and 23. Some members from the collectivist cultures disagree with the statement 24 My subordinates can voice concerns about work goals and statement 25 Other groups plan and coordinate with us. Statement 26 is again agreed upon by almost all the participants. The results in this category reveal a positive ramification for the organization. It shows that the employees have a general agreement about work place goals and they coordinate while setting their goals as a team.

\begin{tabular}{|l|l|l|l|l|l|l|}
\hline & Hindu & Muslim & Buddhist & $\begin{array}{l}\text { Christian } \\
\text { Filipino }\end{array}$ & Anglo & Latin \\
\hline St.21 & $80 \%$ & $80 \%$ & $70 \%$ & $80 \%$ & $80 \%$ & $90 \%$ \\
\hline St.22 & $80 \%$ & $80 \%$ & $80 \%$ & $70 \%$ & $90 \%$ & $80 \%$ \\
\hline St. 23 & $80 \%$ & $70 \%$ & $70 \%$ & $60 \%$ & $80 \%$ & $90 \%$ \\
\hline St. 24 & $70 \%$ & $60 \%$ & $60 \%$ & $60 \%$ & $90 \%$ & $90 \%$ \\
\hline St 25 & $90 \%$ & $80 \%$ & $70 \%$ & $70 \%$ & $100 \%$ & $100 \%$ \\
\hline St.26 & $70 \%$ & $80 \%$ & $70 \%$ & $70 \%$ & $90 \%$ & $90 \%$ \\
\hline
\end{tabular}

Table 6. Comparison of number of participants from each cultural group who agree with the statements in Goal Attainment with others 


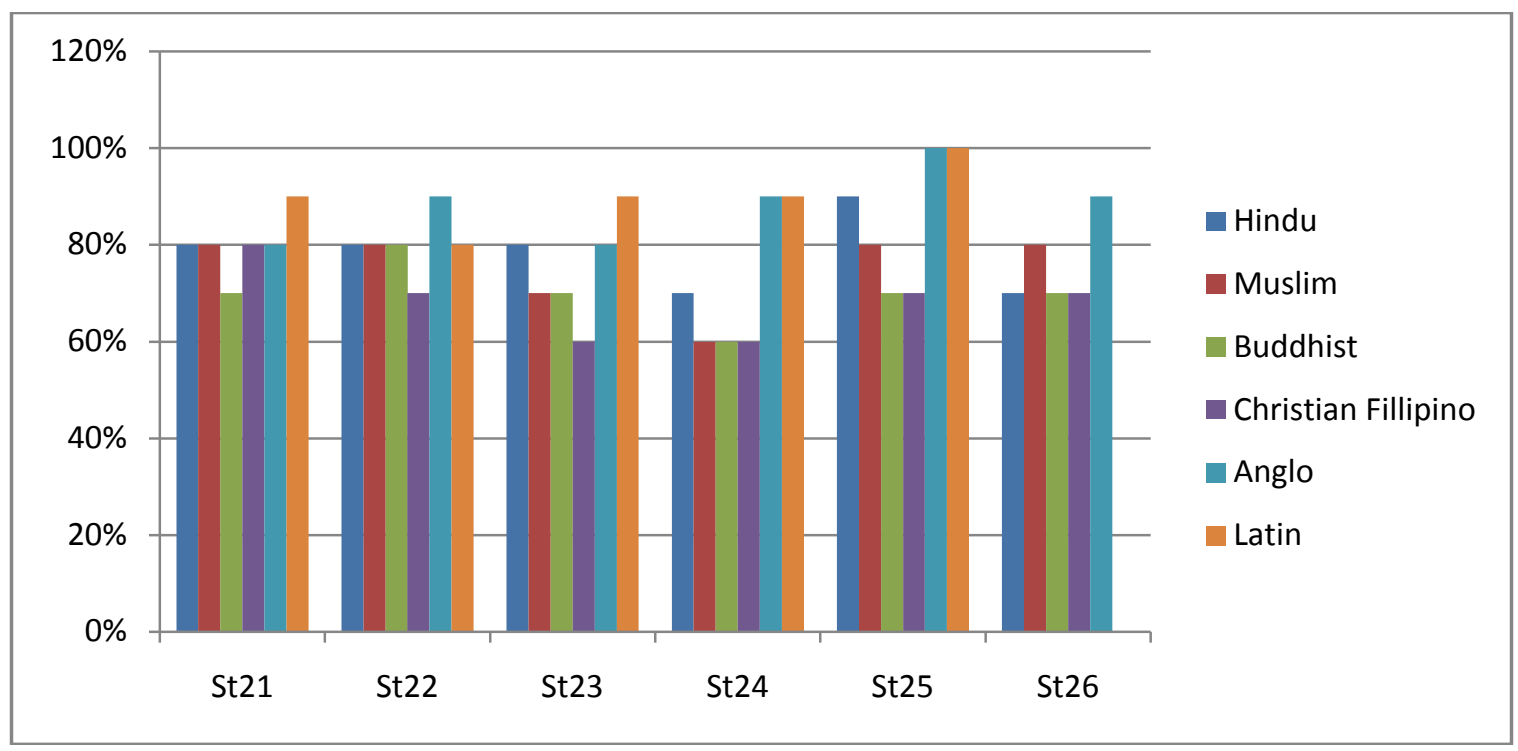

Figure 5. Comparison of number of participants from each cultural group who agree with the statements in Goal Attainment with others scale

The general findings in the above sections reveal that the participants from both of the organizations preferred to frankly communicate the work-place issues with each other and to their supervisors. They preferred less Power Distance and wanted to be communicated the work-place goals. Besides a few respondents, they revealed the personality traits neither too individualist nor too much collectivist. Most of them were aware of how stress affects their performance at work place and how working together to decide and achieve goals as a team is a desirable trait of their job.

\section{Discussion and Conclusion}

The key research question for this research was as follows:

"How do the national cultures of aircraft maintenance personnel impact their workplace attitudes and their response towards the cultures of their colleagues? How do the managers and supervisors deal with the cultural stereotypes and inter-ethnic feuds within their organization?"

The most important finding of this research is that although the characteristics of national cultures impact the attitudes of aircraft maintenance personnel, however, in certain ways, they deviate from their expected cultural traits. There could be a variety of reasons for it e.g. their interaction with their colleagues from all over the globe, their signatory authority, their education in the western countries etc.

In the following paragraphs, the researcher will summarize the findings on the national cultural traits of the participants as framed into the five scales (command responsibility, communication and coordination, avoiding conflict, recognition of stressor effects and goal attainment with others). These five scales address three of the cultural dimensions of Hofstede, which are relevant to the field of aviation. The researcher also observes how these cultural traits impact the work place attitudes and can result in the safe/unsafe flight operations.

One of the key findings is that the AMTs from the collectivist cultures think and make choices like the AMTs from the individualist countries. This is reflected through the data collected on Command Responsibility scale, where the Engineers and AMTs from the collectivist cultures agreed in large numbers that the actions of superiors should be questioned and the technical superiority, not the social connections, make a successful manager. These findings are in line with the findings of Al-Harabi(2001) who posits that the reason for these AMTs to be more individualist is their signatory authority of $\mathrm{A} \& \mathrm{P}$, education and training in Western countries and working and socializing with the Westerners.

The findings on Communication and Coordination Scale contradicted some of the similar researches like Merritt's (1996) and Helmreich and Merritt's (1998). Almost all the participants agreed that good communication and coordination is important for safety but the participants from the collectivist cultures believed that conflicts should not be discussed openly and people should not be criticized publically. 
As far as the findings on the scale of Recognition of stressor effects are concerned, the AMTs from collectivist cultures again reflect individualist tendencies; they express their belief that they should take into account the personalities of other people and they should be sensitive to the problems of other people. However, most of the AMTs displayed a fatalistic attitude towards stress; they believe that fatigue does not impact their performance and their Manager can leave his personal problems behind. This finding is in contrast with that of Al-harabi (2001) and reflects an alarming situation for the organizations.

The findings on Avoiding Conflict Scale again have positive ramifications as almost all the participants see disagreement as a natural phenomenon. However all the participants agreed that they must avoid passing negative comments about other colleagues.

This can be seen as their effort to maintain a pleasant work place environment. Similarly, the findings on goal attainment with others again reflects positive environment as almost all the participants display neither too individualist nor to collectivist tendencies. They preferred less Power Distance and wanted to be communicated the work goals.

These organizations have displayed failure to effectively manage cultural diversity. They also need to address the stereo-typical attitudes of their AMTs and supervisors to enhance their performance. For this purpose, cultural sensitivity programs have to be implemented. The research also revealed that there are no effective training programs organized by the employees which prepare them for the challenges of today's globalized multi-cultural environment.

Some of the other minor research questions addressed in this research were as follows:

1. Do the multicultural settings create stressors which affect job performance? Do the differences of language, culture, religion etc. would negatively impact the job performance?

2. Do the aviation maintenance organizations chosen for the research effectively manage the cultural diversity in their teams?

3. Whether placing maintenance personnel from various nationalities into the same group will negatively impact the job performance, in contrast with the mono-cultural AMT teams?

As far as the answer to No.1 minor research question is concerned, we observe that the multi-cultural settings created a lot of stressors for the aircraft maintenance personnel participating in the research. One of the most problematic areas in this regard has been the differences in the styles of communication. The participants from the individualist cultures tend to speak up against the authority of their supervisors, expressed their opinions directly and criticized the performances of other participants. On the other hand, the participants from the collectivistic cultures tend to see such frank communication as a sign of disrespect, causing them to lose face. Other such problematic situations which were observed during the research were as follows:

a. AMTs and Engineers from individualistic cultures openly criticize the performance of their colleagues from the collectivistic cultures. Such an attitude is seen as a sign of disrespect causing them to lose face.

b. Another such situation is observed in terms of attitudes towards authority. The participants from collectivistic cultures see their manager as their father figure who has to be obeyed in all the circumstances whereas the participants from the collectivistic cultures think otherwise.

The answer to the second minor research question is that aviation maintenance teams need to do a lot more to manage the cultural diversity in their teams. The data generated from interviews clearly prove that point. There is not enough data to give a satisfactory answer to the third minor research question. However the common sense says that the answer to this question is in negative. Multi-cultural teams have been observed performing well and producing outstanding results. However, the cultural diversity needs to be effectively managed.

Concluding, multicultural aviation maintenance teams is a common phenomenon of today's global world however, cultural diversity has to be effectively managed. For this purpose, more research needs to be done and much more efforts need to be put in by the Maintenance organizations to ensure safety of flight operations.

\section{References}

Al-Harabi, Ali (2002) Aviation maintenance in multicultural settings : the challenges of cultural tolerance and of employees' maintenance resource management/human factors (MRM/HF) awareness. 
Hawkins, F.H., \&Orlady, H.W. (Ed.). (1993). Human factors in flight (2nd ed.). England: Avebury Technical, 1993.

Helmreich RL, Merritt AC, Wilhelm JA. The evolution of crew resource management training in commercial aviation.Int J Aviation Psychology. 1998;9:19-32

Helmreich, R.L., \& Merritt, A.C. (1998). Culture at work in aviation and medicine: National, organizational, and professional influences. Aldershot, U.K.: Ashgate.

Hofstede, G. (1980). Culture's Consequences: International Differences in Work-Related Values. Beverley Hills, CA: Sage

Hofstede, G.(1991). Cultures and Organizations: Intercultural Cooperation and Its Importance for SurvivalSoftware of the Mind. Harper Coffins, London

Hoy, Wayne. (1990). Organizational Climate and Culture: A Conceptual Analysis of the School Workplace. Journal of Educational and Psychological Consultation. 1. 149-168. 10.1207/s1532768xjepc0102_4.

Kawar, T.I. (2012) Cross Cultural Differences in Management. International Journal of Business and Social Science.3 (6). Pp. 105-111

Lewis, R. D. (1997). When Cultures Collide: Managing Successfully Across Cultures, Nicholas Brealry Publishing, London.

Merritt, A.C. (1996). National culture and work attitudes in commercial aviation: A cross-cultural investigation. Unpublished doctoral dissertation.The University of Texas at Austin.

Merritt, A.C., Helmreich, R.L., Wilhelm, J.A., \& Sherman, P.J. (1996).Flight Management Attitudes Questionnaire 2.0 (International) and 2.1 (USA/Anglo).(Technical Report 96-04). Austin, TX: University of Texas.

Reason J. Human Error. New York: Cambridge University Press; 1990

Reason J. Managing the Risks of Organizational Accidents. Aldershot, UK: Ashgate; 1997

Rolls Royce (2001). Ten Variables Defined: Analysing Cultural Orientations. Unpublished paper, pp. 1-17.

Sears, R. L. (1986). A new look at accident contributors and the implications of operational and training procedures. Seattle: Boeing Commercial Airplane Company.

Sherman, P. J., Helmreich, R. L. and Merritt, A. C. (1997). National Culture and Flight-deck Automation: Results of a multi-nation survey, pp. 1-15.

Unpublished Ph.D. thesis, submitted at Cranfield University. Downloaded from http://hdl.handle.net/1826/4000

Westrum, R. (1996). "Human factors experts beginning to focus on organizational factors in safety." ICAO journal 51(8): 6.

Wiener, E.L., \& Nagel, D.C. (Eds).(1988).Human factors in aviation. California: Academic Press Inc, 1988 